\title{
Phage display Technology in vitro evolution. Nobel prize 2018.
}

\section{Tecnología de exposición de fagos en evolución in vitro. Premio Nobel 2018.}

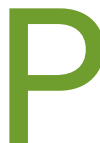

hage display is a laboratory methodology for the study of interactions among proteins which use bacteriophage (virus infecting bacteria) as a main tool where the phenotype can be connected with the virus genotype in the phagic particle. This technique allows a gen which encodes a protein to be cloned and merged with the gen which encodes the phage protein PIII (5 copies) or with the gen which encodes the Protein PVIII (2700 copies) and both exposed in the phage capsid. Proteins, antibodies or cloned peptides are expressed in the phage wrapping and inside we have the gen which encodes it. Libraries or collections of varieties of these molecules may be built and select the one that has the best biological activity when reacting against an immobilized target molecule, this process is called biopanning and imitates the natural selection.

Form the first seeds of live around 3,700 million years ago, almost all Earth cracks have been filled with different organisms. Life has been expanded to all ecosystems from sulfurous waters, the depths of the Marianas trench and dessert zones, because the evolution has solved a number of chemical problems. The chemical tools of life, proteins, have been optimized, changed and renewed, creating an incredible diversity.

The Chemistry Nobel Prizes of this year were inspired in the power of evolution and used the same principle, the genetic change and the selection, to develop proteins that solve chemical problems of humanity.

In 1992 I had the change and honor to work with professor Gianni Cesareni at Universidad de Torvergata in Rome, while I collaborated with the already dead and excellent researchers Ricardo Cortese and Anna Tramontano of the Institute di Ricerca di Biologia Molecolare P. Angeletti SpA (IRBM). For years' important molecules have been obtained from these libraries, used in all knowledge fields.

This year 2018, after 26 years of working with this methodology, I am proud that your researchers were chosen among those awarded with the chemistry Nobel prize. The American George Smith received the Chemistry Nobel Prize, who in 1985 invented this methodology and the British Gregory Winter who remarkably contributed to its development. The other half of the Chemistry Nobel Prize of this year was awarded to the American Frances $\mathrm{H}$. Arnold (fifth woman to receive the Chemistry Nobel Prize) and who in 1993 made the first directed evolution of enzymes which are proteins catalyzing chemical reactions. Since then, the methods have been refined which are usually used to develop new catalyzers.

The Academy emphasizes that with her work the awardees have undertaken the control of evolution and have used it for better benefit of humanity. Enzymes produced by means of directed evolution are used to manufacture any type of products, from biofuel to drugs. Antibodies evolutioned by means of phage display may cure autoimmune diseases and, in some cases, cure metastatic tumors.

Many are the pharmaceutical products useful for men that have been developed with this methodology and represent a simple and economical way of improving the affinity among interactions of proteins greatly used in life sciences.

Figure 1. Nobel prize in chemistry 2018.

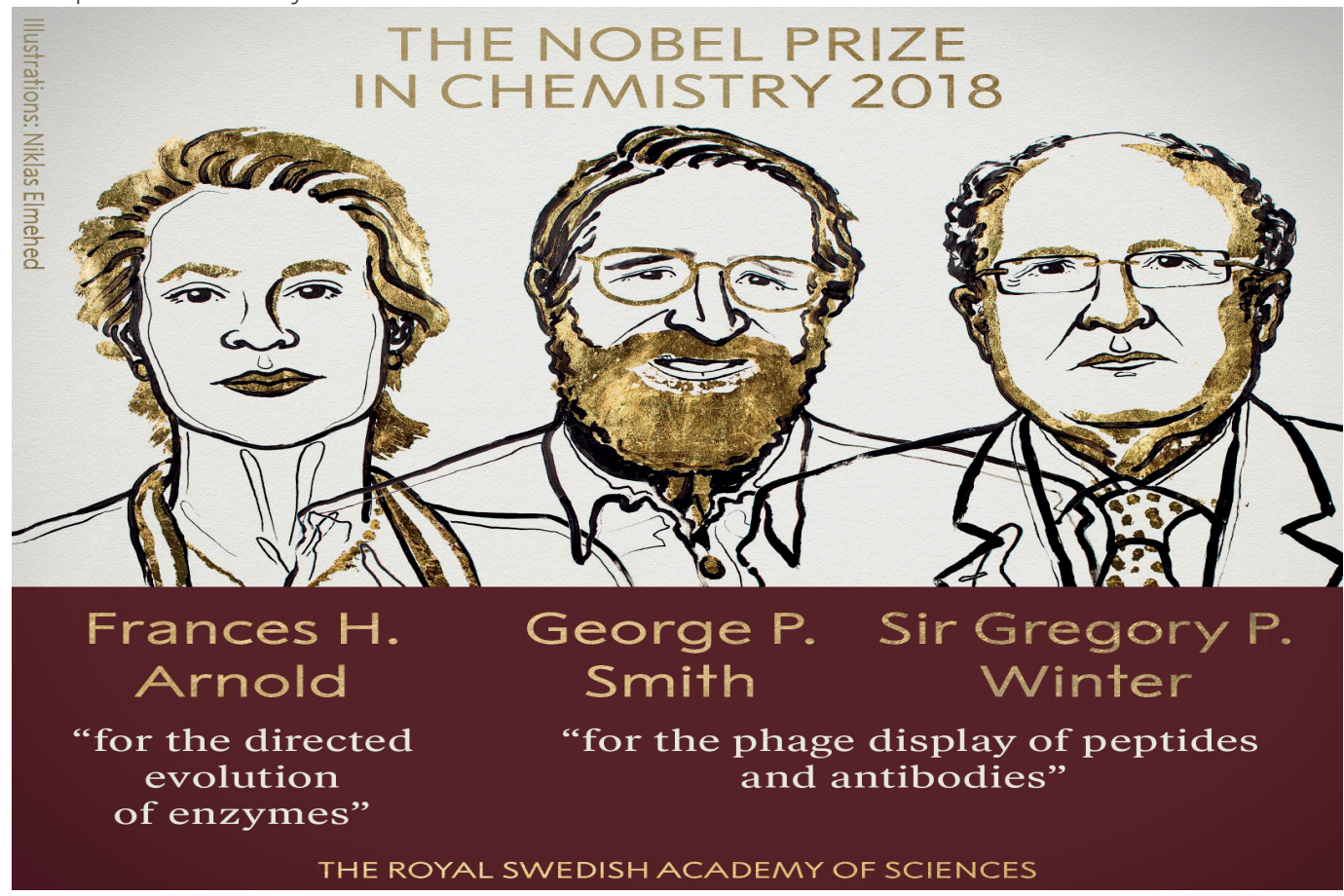

